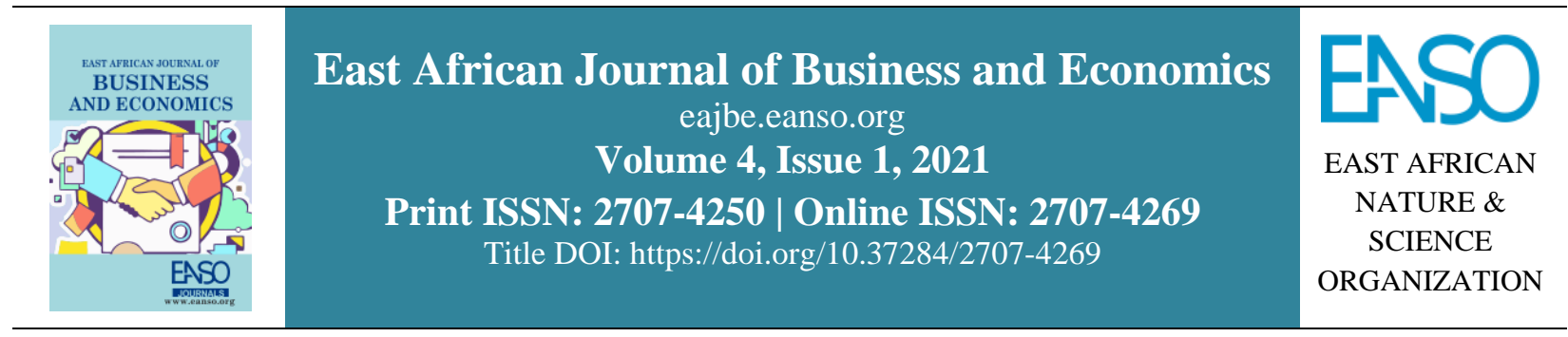

Original Article

\title{
Microfinance Services and the Clients' Socioeconomic Wellbeing During the Covid-19 Pandemic in Uganda.
}

\author{
Dr. James Kizza, $P h D^{1^{*}}$ \\ ${ }^{1}$ Kyambogo University, P. O. Box 12029 Kampala, Uganda. \\ * ORCID ID: https://orcid.org/0000-0002-7253-7734; Correspondence email: kizzajames2016@ gmail.com.
}

Article DOI: https://doi.org/10.37284/eajbe.4.1.510

\section{Date Published: ABSTRACT}

17 December 2021 Microfinance is reported to be an effective tool of empowerment for vulnerable and marginalised groups, especially women. This study set out to investigate

Keywords: the relationship between microfinance services and the clients' socioeconomic

Microfinance Services, wellbeing during the Covid-19 pandemic in Uganda. The study involved 73

Social Services,

Client Protection,

Socioeconomic

Wellbeing,

Covid-19. employees of microfinance institutions that deal directly with the clients. The study findings revealed that while no significant relationship exists between microfinance services and clients' socioeconomic wellbeing, there is a significant moderate positive relationship between microfinance client protection policies and the clients' socioeconomic wellbeing. The regression model revealed that a unit increase in client protection policies increases the socioeconomic wellbeing of microfinance services beneficiaries by $72 \%$. It is recommended that microfinance institutions integrate client protection policies in their activities in line with their known social mission.

\section{APA CITATION}

Kizza, J. (2021). Microfinance Services and the Clients' Socioeconomic Wellbeing During the Covid-19 Pandemic in Uganda. East African Journal of Business and Economics, 4(1), 93-105. https://doi.org/10.37284/eajbe.4.1.510

\section{CHICAGO CITATION}

Kizza, James. 2021. "Microfinance Services and the Clients' Socioeconomic Wellbeing During the Covid-19 Pandemic in Uganda.". East African Journal of Business and Economics 4 (1), 93-105. https://doi.org/10.37284/eajbe.4.1.510

\section{HARVARD CITATION}

Kizza, J. (2021) "Microfinance Services and the Clients' Socioeconomic Wellbeing During the Covid-19 Pandemic in Uganda.", East African Journal of Business and Economics, 4 (1), pp. 93-105. doi: 10.37284/eajbe.4.1.510

\section{IEEE CITATION}

J. Kizza, "Microfinance Services and the Clients' Socioeconomic Wellbeing During the Covid-19 Pandemic in Uganda.", EAJBE, vol. 4, no. 1, pp. 93-105, Dec. 2021.

93| This work is licensed under a Creative Commons Attribution 4.0 International License. 


\section{MLA CITATION}

Kizza, James. "Microfinance Services and the Clients' Socioeconomic Wellbeing During the Covid-19 Pandemic in Uganda.". East African Journal of Business and Economics, Vol. 4, no. 1, Dec. 2021, pp. 93-105, doi:10.37284/eajbe.4.1.510

\section{INTRODUCTION}

Microfinance institutions (MFIs) are socially oriented organisations that offer non-collateralised microcredit to the vulnerable and marginalised groups usually excluded from formal financial institutions. Microfinance has been advocated for as a viable alternative to reach out to the very poor and marginalised groups that are often excluded from accessing finances from the more formalised financial institutions (Busingye \& Kazooba, 2018; Al-Shami et al., 2014; Dhakal \& Nepal, 2016; Kamiza \& Kizza, 2019). MFIs pursue a dual objective of achieving the social mission while at the same time earning some profits to be able to break even (Zamore et al., 2019; Zheng \& Zhang, 2021; Sinha, 2006; Bauwin, 2019). The dual objective pursued by MFIs has been referred to by other scholars as to the double bottom line where the MFIs have a trade-off between serving the marginalised groups (social outreach) and being able to break even (financial sustainability). The pursuit of this dual objective is cited among the key features that distinguish a commercial bank from a microfinance institution (Zheng \& Zhang, 2021). The social objectives of the MFI imply that the MFIs have a social responsibility to protect the clients' interests, the staff, the community as well as the environment which becomes even more pertinent during the Covid-19 pandemic (Sinha, 2006).

In Uganda, the government declared a countrywide lockdown to curb the spread of Covid-19 from March 18, ${ }^{2020}$ and went almost up to the end of September 2020. In June 2021, another lockdown that lasted for the full month was effected (Kizza et al., 2021; Muzee et al., 2021). To date, certain sectors of the economy are yet to be opened which has driven a reasonable proportion of the population into significant vulnerability levels. Some of the sectors that have remained closed to date include the education sector and the entertainment industry, which hitherto employed a sizeable segment of the country's population. A proportion of the population that deals in activities related to these sectors have been left with no structural source of income and yet some of these have been the actual and potential clientele of microfinance institutions. Focussing on lending to the vulnerable and marginalised groups is associated with a high risk of default rate, and this is worsened by crises such as that caused by the unprecedented lockdowns of economies due to the Covid-19 pandemic. Whereas MFIs were not closed per se during the lockdown in Uganda, the restrictions on social gatherings limited the effective utilisation of group lending methodologies to advance and monitor extended credit. By implication, MFIs became prone to high levels of liquidity risk, yet at the same time, the increase in the number of vulnerable groups may have raised the demand for microcredit (Abrams, 2021), or possibly decreased the demand for credit as the case was among most MFIs in Europe (Dąbrowska et al., 2020).

Whereas a crisis situation worsens the financial efficiency of MFIs, it positively improves MFIs' social efficiency as it responds to meet the needs of the vulnerable groups (Zheng \& Zhang, 2021). The disruptions caused by Covid-19 have adversely impacted microbusinesses and people's livelihoods (Abrams, 2021). When people are locked down in their villages or homes, their ability to carry out productive economic activities is reduced. As a result, the demand for microcredit and the ability to pay earlier loans accessed becomes a problem, which may increase the MFIs portfolio at risk. What then gives the urge to the microfinance institutions (MFIs) to venture into such high-risk activities of continually looking out for the vulnerable even during periods of increased uncertainty? This can be partly answered by assessing the potential sources of funding to microfinance institutions that include: governmental agencies, integration of cost recovery interests in the loan advanced, donors, charities, commercial banks, insurance companies and private equity firms that may offer concessional loans to MFIs which are viewed as key partners in uplifting the socioeconomic status of the vulnerable and marginalised groups (Postelnicu \& Hermes, 2018; Al-Shami et al., 2014)

The social objective pursued by the MFIs is normally measured in terms of the impact or change 
that is attributable to the MFI intervention (Sinha, 2006). The intervention should lead to improved livelihoods of the marginalised groups as manifested in the increase in the number of vulnerable and marginalised groups accessing microfinance services. The social impact of microcredit can also be measured by the number of jobs created, improved access to medical care, access to education, reduced dependency on moneylenders, more income-generating activities set up, improved household income and generally, women empowerment (Sinha, 2006). The viability of the attainment of the social objective by MFIs whose client vulnerability is increased by highly restrictive lockdowns and unprecedented disruptions in production is worth investigating and is the subject of the current study. We hypothesise that: 1) The microfinance social services do not lead to improved socioeconomic wellbeing during the pandemic; 2) the microfinance client protection services do not lead to improved socioeconomic wellbeing during the pandemic

\section{LITERATURE REVIEW}

\section{Microfinance and the Covid-19 pandemic}

Whereas the majority of the MFIs have not reported liquidity problems during the pandemic, a small percentage of MFI clientele reported gains in income during the pandemic (Dąbrowska et al., 2020). Dąbrowska et al. (2020) investigated the initial impacts of the Covid-19 pandemic on MFIs and their clientele and made an observation that the crisis has affected the MFIs and clientele differently depending on the type of economic activities engaged in by the MFIs clients. The study reports several challenges faced by MFIs clients including but not limited to restarting their business activities and adapting to the new normal of the increased use of technology that thrives in the virtual environment. The disruptions of Covid-19 in the work environment and the increased utilisation of the virtual space to further organisation objectives are discussed at length in the article authored by Muzee et al. (2021).

The pandemic has disrupted the dual objective of the MFIs as some MFIs reported deteriorations in portfolio quality (PAR30) even in light of stringent credit assessment policies that disoriented the majority of the marginalised and vulnerable groups. MFIs have had to incorporate a new risk (the Covid19 risk) in their risk management policies on top of being innovative in reaching out to clients restricted to their homes through virtual communication tools like Skype, WhatsApp and zoom. The setting of this study is in Europe, which may not readily apply to the underdeveloped economy like Uganda, where the current study is set. Despite this difference in the study setting, the effects of the Covid-19 pandemic on MFIs operations worldwide may draw commonalities and the difference may be in the policy responses that are context-dependent. The study points out that the pandemic may affect more MFIs that rely on savings to advance credit as is the case in some Sub-Saharan African Africa than MFIs in Europe that are not allowed to take deposits.

\section{Empirical Studies}

Busingye and Kazooba (2018) conducted a study investigating whether the outcomes of microcredit led to the empowerment of female-headed families in Uganda. The study findings revealed that much as microcredit provided sources of funding to set up income-generating activities (IGAs) and other related money transfers that generally led to improved incomes and household wellbeing, many female households continue to be poor and marginalised. The study recommended the development of more flexible products that are addressed to meet specific gender needs.

Zheng and Zhang (2021) investigated the effect of Covid-19 induced decline in economic activities on the financial and social efficiency of MFIs. They hypothesised that: H1 Covid-19 induced economic slowdown is negatively associated with MFI financial performance and $\mathrm{H} 2$ Covid-19 induced economic slowdown is positively associated with MFI social performance. Based on the study findings, they reached a conclusion that while the financial efficiency of MFIs is lower, the social efficiency of MFIs increases during the crisis. The unfortunate fact is that the improvement in social efficiency is enabled by the increased demand for highly-priced microloans that the poor resort to because of their failure to access loans from commercial banks. The point of contention is whether the social efficiency of MFIs can translate 
into a positive socioeconomic impact on the marginalised and vulnerable groups.

Dhakal and Nepal (2016) investigated the contribution of microfinance to the socioeconomic development of a rural community in the Syangja district following a quantitative approach and a cross-sectional study design. The respondents were purposively selected and the perceptual analysis revealed that microfinance significantly contributes to social change and development. The study concluded that if microfinance services are to be provided efficiently, the internal management of microfinance institutions needs improvement

Murad and Idewele (2017) investigated the impact of MFIs on the economic growth of Nigeria using secondary commercial banks in Nigeria. The study period ranged from 1992 to 2012, which is timeseries data that was analysed using multiple regression analysis. The study findings revealed that microfinance loans have a significant positive impact on the short-run economic performance manifested in an increase in consumption, which impact did not progress into the long run. The study revealed the strategic position of microfinance in the improvement of the socioeconomic wellbeing of vulnerable and marginalised groups. The investment in microfinance, however, impacted positively on the economic performance of Nigeria in the long run. The study recommended that MFIs continue to loan in the short run to improve consumption and in the long-run endeavour to improve microfinance investment augmented with other policy measures that will enable sustainable growth of the economy.

Kamiza and Kizza (2019) investigated the contribution of microfinance products towards the socioeconomic growth of entrepreneurs in Uganda. The study findings revealed that microfinance products make a significant contribution to the clients' socioeconomic growth. The study recommended that microfinance services be made easily accessible to the targeted population. This study concentrated on the loan, savings and money transfers without handling the aspect of client protection that the current study tries to bring into perspective. The study was also conducted before the emergency of Covid-19, and as such the study findings may have lost relevance given the current prevailing conditions.

\section{Microfinance Services and the Socioeconomic Wellbeing of Vulnerable and Marginalised Groups}

Microfinance services refer to both the financial and non-financial services offered by MFIs to their beneficiaries. Microfinance services can be broadly categorised into financial and social intermediation. The financial intermediation services include the provision of microloans with little or no collateral to vulnerable and marginalised groups. Lending to the poor who even cannot provide collateral possesses an inherent liquidity risk, but, following the example of the Grameen Bank, this risk is normally managed through group lending methodology (Armendáriz \& Morduch, 2005). The social intermediation services consist of non-financial services offered to MFIs clients such as training in financial literacy and business development related services in entrepreneurship and business planning. Microfinance is thus not only limited to the promotion of business development but also includes the whole range of services aimed at improving the economic wellbeing of households. Microfinance is associated with a significant positive impact on the client's wellbeing (Al-Shami et al., 2011; Kamiza \& Kizza, 2019). This study measures microfinance services in terms of social and client protection services offered to the vulnerable and marginalised groups during a crisis situation such as that induced by the Covid-19 pandemic.

The two main product offerings of most MFIs are loans and savings. The saving services offered by MFIs include mandatory (compulsory) savings that MFIs require clients to save as a prerequisite to accessing loans. The mandatory savings help the MFIs to somehow reduce the risk associated with lending to the poor without collateral and provide the MFIs with low-cost capital that helps to improve their financial sustainability (Al-Shami et al., 2014). Other saving products offered by MFIs range from accepting voluntary savings, insurance deposits and money transfers (Murad \& Idewele, 2017; Kamiza \& Kizza, 2019). The loan services offered by MFIs are microloans, at times referred to in the literature as microcredit. Microcredit accompanied with non- 
financial services (microcredit plus) such as entrepreneurship and business skills training are associated with more socioeconomic impact on the clientele (Sigalla \& Carney, 2012; Bauwin, 2019). Various scholars advocate the need for MFIs to provide an enriched menu of services that integrate the non-financials into the financial services to make microfinance more effective (Magner, 2007). Hamdan et al. (2012) underscore the need for MFIs to provide non-financial services to the clients in the form of entrepreneurial and business skills training to enable them effectively utilise the accessed funds. Clients trained in entrepreneurship and financial literacy may not only create more job opportunities but their ability to honour their loan repayment schedules will improve, and where women are involved, it will promote women entrepreneurship (Al-Shami et al., 2014; Darin-Mattsson et al., 2017; Kåreholt, 2017; Mayoux, 1999)

The socioeconomic impact of microcredit is to lead to changed lives where the vulnerable gain societal respect, gain self-employment, can afford adequate housing, pay for their children health and medical bills, good feeding, increased participation in decision making, happy and stable families, improved self-esteem of the marginalised, and widened life choices including enjoyment of leisure opportunities (Dhakal \& Nepal, 2016). The loan services offered to the marginalised are known to be more impactful to the client's wellbeing if offered in time with a flexible loan repayment period, with loan terms made clear to the client and at an affordable interest rate (Al-Shami et al., 2014). The clients' characteristics such as gender, religious affiliation and education level are some of the key determinants of loan repayment terms (Nawai \& Shariff, 2012)

Clients' wellbeing refers to the household empowerment and improvement in the livelihoods as manifest in the clients' ability to meet the basic necessities of life such as feeding, shelter, education, health and access to employment. Microfinance is reported to be an effective tool of empowerment for vulnerable and marginalised groups, especially women (Al-Shami et al., 2014). The increased focus on women and other vulnerable groups can be easily measured when we consider the number of women and groups considered vulnerable accessing credit at a given period
(Bauwin, 2019). Economic empowerment is manifest in borrowers improved savings, incomes, self-employment, acquisition of more household assets and ability to repay the borrowed funds (Busingye \& Kazooba, 2018)

MFIs are known to utilise commercial means to fulfil their social mission of reaching out to vulnerable and marginalised groups (Dąbrowska et al., 2020). Socioeconomic wellbeing is closely associated with the quality of life lived by the people, which is greatly improved by the level of social support that people can receive from other members of the community. The group lending methodology used by MFIs as a substitute for collateral, much as it is more of a financial tool, provides an opportunity for group members to build on the needed social capital. Social capital helps members to live their lives fully by sharing their experiences with each other, which helps them, manage life-related stress related to feelings of loneliness.

The literature identifies several measures of socioeconomic wellbeing focussing on the basic needs of man such as education, health, housing, feeding, employment, income and gender equality. An improvement in socioeconomic wellbeing is indicated by measures such as a reduction in unemployment rates, improvement in life expectancy, improvement in people's living conditions and improved school enrolment rates of the marginalised and vulnerable groups (DarinMattsson et al., 2017). The literature, however, post diverging opinions on the effectiveness of microfinance in leading to positive change in the livelihoods of the marginalised, with some studies posting no impact in the short run while other studies post positive impacts in the long run enabled by the current investments that eventually translate into higher spending in the future on key social indicators such as education and health (Bauwin, 2019)

\section{Microfinance Social Services and Clients Socioeconomic Wellbeing}

The literature surveyed reveals that microfinance is associated with an improvement in the socioeconomic wellbeing of the beneficiaries (Busingye \& Kazooba, 2018; Kizza \& Ssekibaamu, 
2019). When the vulnerable access to credit is eased, their capabilities are enhanced. Through the microfinance extended to the vulnerable, they are enabled to set up income-generating activities, improve their saving levels, pay for the education of their children as well as improve their voice in the decision-making process. The group lending methodology normally based on by many microfinance institutions offers an opportunity to the vulnerable groups to build on their social capital through the increased opportunity to interact with members of the group, and of course, their financial advisor who is responsible for monitoring their loan repayment. The access to group loans is taken to be positively associated with female entrepreneurship and household food consumption. When group loans are applied as substitutes to collateral, it may lead to the more appropriate use of the borrowed funds since it contains aspects of joint liability. The group lending methodology is beneficial to the MFIs as well as it substitutes for the absence of collateral on credit advanced (Armendáriz \& Morduch, 2005). The group lending methodology has also proved to be an effective hedge for MFIs against financial risk during crisis situations (Zamore et al., 2019).

The literature identifies the number of females accessing credit as an indicator of MFIs meeting their social objective of reaching out to the very poor (Busingye \& Kazooba, 2018; Bauwin, 2019). The social impact is said to be even more felt in crisis situations like that experienced during the Covid-19 pandemic. When a microfinance institution advances credit to an individual or group, it expects timely recovery of the disbursed funds. However, during a crisis situation such as that experienced during the Covid-19 pandemic, loan repayment schedules are threatened by governmentimposed lockdowns that disrupt both social and economic activities (Zheng \& Zhang, 2021).

In a bid to meet their operational costs that are aggravated by the high costs associated with loan recovery measures, MFIs tend to charge highinterest rates to their clients, their vulnerable position notwithstanding (Kamiza \& Kizza, 2019). The poor continue to seek out these highly-priced loans, as this is their only plausible option given the reluctance of commercial banks to advance credit to the poor due to their lack of collateral. The social efficiency of MFIs is said to improve during crisis situations as the MFIs are motivated to reach out to the very poor through the provision of microloans, albeit at high-interest rates (Zheng \& Zhang, 2021; Dhakal \& Nepal, 2016). The high lending rates have been justified not only as a solution to the high cost of lending experienced by MFIs but also as an enabling mechanism for the MFIs to expand their outreach to the vulnerable groups. This study takes a critical analysis to understand the implications of such highly-priced loans on the socioeconomic wellbeing of the MFIs targeted clientele.

\section{Microfinance Client Protection Services and Clients Socioeconomic Wellbeing}

Client protection is taken to refer to the measures undertaken by a microfinance institution to ensure that the credit advanced to clients does not harm further their disadvantaged position. This can be achieved by the MFIs ensuring that while advancing credit, the ability of the client to pay the loan advanced is taken into consideration. Other protection measures include client education, especially on how to utilise the loan advanced, timely reminders of loan repayment and affordable interest rates. In crisis situations like during the Covid-19 pandemic, client protection includes measures taken by the MFI to protect both the health of staff and clients. Microfinance relies heavily on group lending methodology to substitute for collateral that the vulnerable groups tend to lack. To ensure clients are protected from the adverse effects associated with loan mismanagement, microfinance usually organises client education to the established groups on the dos and don'ts of the borrowed funds before credit is finally disbursed to the group. Usually, the group selects a leader who works closely with the microfinance financial advisor to ensure group members use the advanced credit as agreed and do not default on the agreed repayment schedules.

The repayment schedule is normally explained to the group and is agreed upon. The advantages of timely meeting the agreed-upon repayment schedules, such as ease of access to future larger loans are explained. The disadvantages of defaulting on the schedule are also explained, and this may include penalties on the loan default and loss of access to future loans. First-time borrowers 
are normally advanced smaller loan amounts which progressively are increased as the microfinance institution monitors the capacity and credibility of the individual borrower or group in timely meeting the financial obligations of credit advanced. The microloans are intended to protect the client from the risk associated with high levels of indebtedness (Dąbrowska et al., 2020).

Some microfinance institutions require borrowers to make compulsory savings, which are based on determining the amount of loan. The compulsory saving requirement is such that the intending borrower deposits at least thirty per cent (30\%) of the needed credit. Whether this thirty per cent is a good indicator of the ability of the borrower to repay the loan advanced may need further investigation. At face value, we can argue that the thirty percent is taken as a commitment by the prospective borrower to repay the loan advanced to him or her. The thirty percent may also have been built on the principle that the beneficiary needs to actively participate in the activities intended for his/her own benefit if s/he is to take ownership of the said activities. In Keynesian economics, savings is what is left of a person's income after meeting his/her tax obligations and consumer needs. Savings are a key aspect of what is needed to drive the growth of the economy as savings enable investment, which leads to increased capital accumulation.

Client protection would imply the ability of MFIs to promote activities that promote the wellbeing of their clientele. Before a loan is advanced, it is important that due diligence is exercised to ensure the client's ability to repay the loan advance. This would also require the MFI to provide all the necessary information to the clientele about the loan terms and conditions. This information may include but is not limited to providing information to the clientele on the interest rate payable on the loan, the repayment schedule, the opportunities available for possible loan re-scheduling in times of crises and the implications thereof. Client protection is also manifest in the appropriateness and transparency exhibited in the services offered by MFIs, such as flexible loan repayment terms, competitive interest rates and tailored loan products. Client protection also necessitates that MFIs timely handle customer complaints, monitor clients loan schedules and adopt appropriate debt repayment practices (Sinha, 2006)

The protectionist policies of MFIs become even more pertinent in a crisis like that caused by Covid19, where the protection covers not only the financial but also other aspects of life including the health of both the clients and the staff. The measures put in place to protect the staff and clients like the purchase of sanitisers and facemasks constitute a cost that may not have been planned for in the already high administrative costs of the MFIs. The social distancing measures that have been maintained up to now since March 2020 led to the doubling of transport costs, which means MFIs, have to incur more costs in loan monitoring without necessarily integrating this cost in the price of credit given that the population is already financially constrained. The complexities around all this are the subject of this study as we try to explore how such protectionist policies of MFIs impact the socioeconomic wellbeing of the clientele during periods of crisis and uncertainty.

\section{Gender Relations and Socioeconomic Wellbeing}

From the very beginning, microfinance was basically viewed as needed to help the marginalised, especially women and the poor. From our study, we try to establish who benefits more from the microfinance services, is it the original target of the identified vulnerable groups such as the women and the youth or with time have this noble objective been neutralised by more males seeking microfinance services. The neoliberal development model advance microfinance as a key tool needed to support women's economic empowerment (Gupta, 2014). This presupposes that the women access the microfinance without any external pressure such as at times when husbands force their wives to obtain microcredit, which the husbands make use of to repay the loan, though this distorts the noble objective of microfinance (Rahman, 1999) Whereas some studies indicate that microfinance promotes women's empowerment, other studies have found men to be the major beneficiaries and the impact on women empowerment has been found to be insignificant (Bauwin, 2019).

According to Sinha (2006), whereas some MFIs services generally target the vulnerable and the 
marginalised without specificities, some are focussed specifically on serving women and others on serving men. The Grameen Credit Agricole Foundation is one of the institutions that has gained repute for prioritising women and the rural population in its financial and related social activities (Abrams, 2021).In the same vein, while some MFIs apply a group model based on social collateral, others apply an individual model while others apply a mixture of both the group and individual models. The literature provides several reasons as to why microfinance may fail to improve the socioeconomic wellbeing of vulnerable and marginalised groups. Among the reasons advanced to include the use of microfinance to fund more of consumption than investment, the high cost of credit that increases the clients' indebtedness, the lack of innovativeness in business created by clients leading to limited demand and the consequent business failure as well as the growing inclination towards microfinance commercialisation that has resulted into exploitative policies to the vulnerable and marginalised groups (Bauwin, 2019)

\section{MATERIALS AND METHODS}

The study was conducted during the Covid-19 pandemic, where some sectors of the economy are still under lockdown. The quantitative approach was taken to collect information from the respondents who were the employees of MFIs covering various fields of microfinance services in the Central and Eastern regions of Uganda. All 73 employees of
MFIs composed of managers and relationship officers participated in the study. 42 (56\%) of the respondents had worked with the MFI for a period between 1 to 10 years. Most of the respondents of MFIs were surprisingly male $(40,55 \%)$. Many of the respondents were single $(40,55 \%)$ and possessed at least a first degree $38(52 \%)$. The respondents filed a self-constructed questionnaire that followed a five type Likert scale where 1 represented disagreement with the item under consideration and 5 showed agreement with the item under consideration. To ensure the validity and reliability of the study instruments, Pearson's product-moment correlation and Cronbach alpha coefficient were estimated. The obtained Cronbach alpha coefficient of 0.86 exceeded the minimally acceptable range falling in the range of very good (Tavakol \& Dennick, 2011) implying that the study instrument was highly reliable. The collinearity tolerance (1/VIF) for all predictor variables was greater than $0.1(10 \%)$ with the corresponding variable inflation factor (VIF) for all variables not less than 1 which falls within the recommended interval of 1 and 10 indicating the nonexistence of multicollinearity in our data set. The estimators were this considered reliable. All the data analysis in this study was done using Stata 12 software. The descriptive statistics were generated, correlation tests performed and the multiple regression and parameter estimate was conducted to determine the contribution of each predictor variable to the dependent variable. The theoretical model that guided the study is given by:

Socioeconomic wellbeing ${ }^{(Y)}=\alpha+\beta_{1} X_{1}+\beta_{2} X_{2}+\varepsilon$ Where $\alpha$ is the intercept $\beta_{1} \beta_{2}$ are Coefficients $X_{1}=$ Social services $\quad X_{2}=$ Client protection policies and $\varepsilon$ - error term

\section{RESULTS}

The overall means of the study constructs revealed respondents' agreement with the various items under each construct. The overall means and standard deviation (SD) of the various constructs under study were $3.69 \pm 0.5$ for social services, $3.85 \pm 0.3$ for client protection and $3.79 \pm 0.51$ for socioeconomic wellbeing. The findings on MFIs services revealed that MFIs provide clients with adequate information about the loan terms, educate clients on how to repay the loan, offer affordable interest rates and make their services easily accessible to the clients. However, less priority was given to loans meant for the acquisition of household assets and basic necessities.

In a bid to promote social efficiency, MFIs have policies aimed at client protection. These policies include but are not limited to constantly reminding clients when the debt falls due, being cautious about clients engaging in multiple borrowing, provision of financial literacy before loan extension, due diligence is done during loan screening and timely response to client's queries. Given that we are in periods of a Covid-19 pandemic, MFIs adopted 
policies aimed at protecting the clients' health in line with the recommended standard operating procedures (SOPs). The results indicate that MFIs have focussed more on the provision of handwashing facilities to the clients as opposed to providing clients with face masks.

The impact of the MFIs services is reflected in the improvement in the clients' income, improvement in the number of women accessing microcredit,

\section{Correlation Results}

\section{Table 1: Correlation matrix}

more clients reporting ability to educate their children, increased opportunities for client protection, improvement in clients' savings, growth in the number of incomes generating activities and the general growth of female entrepreneurship in the areas studied. However, the results revealed a wide difference among the respondents on the number of youths accessing loans, clients reporting improvement in housing and feeding patterns.

\begin{tabular}{lllll}
\hline & Social services & $\begin{array}{l}\text { Client } \\
\text { policies }\end{array}$ & protection & Socioeconomic wellbeing \\
\hline Social services & 1 & & \\
Client protection policies & 0 & 1 & 1 \\
Socioeconomic wellbeing & 0.1 & $0.5^{* * *}$ & \\
\hline$* * *$ significant at 5\% & & &
\end{tabular}

The correlation tests were done to test the relationship between the independent variables and the response variable. The results indicate:

\section{$H_{1}$ : The microfinance social services do not lead to improved socioeconomic wellbeing during the pandemic}

The results indicate that microfinance social services do not lead to improved socioeconomic wellbeing during periods of the pandemic $(0.1$; $p \succ 0.05$ ). The null hypothesis is upheld.

\section{$\mathrm{H}_{2}$ : The microfinance client protection services}

do not lead to improved socioeconomic wellbeing during the pandemic

Table 2: Regression test (parameter estimates)
The results indicate the existence of a significant positive relationship between microfinance client protection services and clients' socioeconomic wellbeing during periods of the pandemic (0.5; $p \prec 0.05$ ). This means that microfinance client protection services moderately positively contribute towards clients' socioeconomic wellbeing during periods of the pandemic. The null hypothesis is rejected.

\begin{tabular}{lllllll}
\hline Variable & Coef. & Std. Err. & T & P>t & [95\% Conf. & Interval] \\
\hline Social services & 0.1 & 0.11 & 0.93 & 0.36 & -0.12 & 0.33 \\
Client protection policies & 0.72 & 0.16 & 4.4 & 0 & 0.39 & 1.04 \\
Intercept & 0.64 & 0.74 & 0.85 & 0.4 & -0.85 & 2.12 \\
\hline
\end{tabular}

The estimated equation as derived from Table 2 is given as ${ }^{(Y)}=0.64+0.72 X_{2}$. These findings imply that a unit increase in client protection policies increases the socioeconomic wellbeing of microfinance services beneficiaries by $72 \%$. This can be explained by the fact that the target clientele of microloans are the marginalised and vulnerable groups that may not realise the benefits of microloans unless the MFIs take deliberate efforts to protect them from the potential adverse effects of microloans, especially during periods characteristic of disruptions in production and consumption. 
East African Journal of Business and Economics, Volume 4, Issue 1, 2021

Article DOI: https://doi.org/10.37284/eajbe.4.1.510

Table 3: Regression model summary

\begin{tabular}{lllllll}
\hline Source & SS & df & MS & Number of obs & $=$ & $\mathbf{7 3}$ \\
& & & & F $(2,70)$ & $=$ & 10.25 \\
Model & 4.2 & 2 & 2.1 & Prob $>$ F & $=$ & 0.00 \\
Residual & 14.33 & 70 & 0.2 & R-squared & $=$ & 0.23 \\
& & & & Adj R-squared & $=$ & 0.20 \\
Total & 18.52 & 72 & 0.26 & Root MSE & $=$ & 0.45 \\
\hline
\end{tabular}

The regression test was performed to determine the contribution of the independent variables on the response variable and also help to model the relationship between the independent variables and the response variable. Collectively, the predictor variables explain $20 \%$ of the variation in microfinance clients' wellbeing (Adjusted Rsquared $0.20 ; p<0.00)$. The difference between the $\mathrm{R}$-squared and the adjusted $\mathrm{R}$ - squared is only 0.03 , meaning that the model fit is very good. The F-test is also significant which implies that our regression equation fits well the data set used in the analysis.

\section{DISCUSSION, CONCLUSIONS AND POLICY RECOMMENDATIONS}

The paper sought to establish if microfinance services had any relationship with the clients' socioeconomic wellbeing during the Covid-19 pandemic and the results, in general, indicate that among the microfinance services studied, the client protection policies are a significant predictor of clients' socioeconomic wellbeing when compared to the microfinance social services. The correlation results indicated that microfinance social services do not lead to improved clients' socioeconomic wellbeing contrary to earlier findings of studies done by (Kamiza \& Kizza, 2019; Dhakal \& Nepal, 2016; Al-Shami et al., 2014; Mokhtar, 2011; Kizza \& Ssekibaamu, 2019). The non-significant relationship between microfinance social services and the clients' socioeconomic wellbeing may be explained when we make an analysis of the adoption of the virtual workspace that some MFIs have adopted to reach out to the clientele yet the majority of the clientele are not accustomed to the use of virtual tools. The virtual tools also limit the benefits associated with face-to-face interactions among group members that seek for or are managing the received microloan. Much as the pandemic periods tend to increase the social efficiency of MFIs, this is normally achieved at the expense of the clients that have to obtain highly-priced microloans, thereby reducing the expected positive socioeconomic impact of the microloans on the marginalised population (Zheng \& Zhang, 2021).

The results seem to suggest the existence of a wide variation in opinion as to whether MFIs are still focussed on their primary mission of serving the vulnerable and marginalised in society. This variation seems to be supported by the research findings that question the effectiveness of microloans in improving the livelihoods of women and the marginalised (Busingye \& Kazooba, 2018; Bauwin, 2019; Gupta, 2014; Rahman, 1999). Despite this variation in opinion, there is still agreement that MFIs give preference to women borrowers and rural borrowers. The respondents also varied on the purpose of loan provision, especially as regards the provision of loans to enable clients to acquire household assets or acquire necessities. This may be explained by the need for MFIs to manage liquidity risk by lending into activities that are meant to generate more income than activities that can be considered more of consumption in nature (Dąbrowska et al., 2020). The apparent non-significant relationship between microfinance services and the clients' socioeconomic wellbeing does not, therefore, come as a surprise. MFIs lending for consumption is associated with improvements in clients' socioeconomic wellbeing (Murad \& Idewele, 2017).

The results revealed the existence of a significant moderate positive relationship between microfinance client protection services and clients' socioeconomic wellbeing during periods of the pandemic. Client protection through microcredit plus is supported by several research studies as having a positive impact on clients' economic wellbeing as the study findings have revealed (Sigalla \& Carney, 2012; Hamdan et al., 2012; 
Magner, 2007; Darin-Mattsson et al., 2017; Mayoux, 1999). The study revealed several client protection policies that MFIs offer to the clientele including but not limited to: educating clients before extending credit, constant reminders on debt repayments, timely handling of complaints and thorough client screening. To protect the clients' health during the pandemic, handwashing facilities have been prioritised ahead of providing face masks to clients.

The study findings revealed that a unit increase in client protection policies increases the socioeconomic wellbeing of microfinance services beneficiaries by $72 \%$. This can be explained by the fact that the target clientele of microloans are the marginalised and vulnerable groups that may not realise the benefits of microloans unless the MFIs take deliberate efforts to protect them from the potential adverse effects of microloans, especially during periods characteristic of disruptions in production and consumption. The extension of microloans to support the socioeconomic wellbeing of the vulnerable and the marginalised is supported by (Sinha, 2006). Client protection policies are also in line with the social objective of microfinance institutions.

The impact of microfinance services on the clients' socioeconomic wellbeing in the study was manifested by the agreement of the respondents on aspects such as a record of improvement on clients' income, more women accessing loans, growth in clients' social capital, more children enrolled in schools, improvement in clients' savings and ability to repay the loans advanced, growth in female and youths entrepreneurship, more income-generating activities set that increased employment opportunities, improvement in clients' self-esteem, increased access to health facilities, growth in household assets and more clients opening up accounts in formal financial institutions. These findings are in agreement with earlier studies that attribute the improvement in socioeconomic wellbeing of the vulnerable and marginalised groups to the microfinance services (Kamiza \& Kizza, 2019; Dhakal \& Nepal, 2016; Al-Shami et al., 2014; Mokhtar, 2011; Kizza \& Ssekibaamu, 2019; Sinha, 2006). The findings post a lower level of agreement and a wider variation in opinion towards the effectiveness of microfinance services in leading to clients' improved housing and feeding patterns. This may be explained by the fact that MFIs tend to prioritise borrowing to set up incomegenerating activities as opposed to financing consumption activities.

Based on the above research findings, we recommend that policymakers and MFIs prioritise client protection policies in their activities. The findings have clearly revealed that the extension of microfinance services without corresponding appropriate client protection policies may not yield the desired improvement in the socioeconomic wellbeing of the marginalised and vulnerable groups. The findings are a reminder to the microfinance institutions to always reflect on their social mission in all their activities.

\section{REFERENCES}

Abrams, J. (2021). Crisis road map for microfinance institutions: COVID-19 and beyond. CGAP/World Bank,2021.

Al-Shami, S. S. A., Majid, I. B. A., Rashid, N. A., \& Hamid, M. S. R. B. A. (2014). Conceptual framework: The role of microfinance on the wellbeing of poor people cases studies from Malaysia and Yemen. Asian Social Science, 10(1), 230.

Armendáriz, D. A., \& Morduch, J. (2005). The Economics Microfinance. UK: Cambridge, MA: The MIT Press. CGAP (2013).

Bauwin, B. (2019). Social Performance Management in Microfinance: Practices, Results and Challenges. ADA.

Busingye, J., \& Kazooba, C. (2018). Micro credit and women empowerment: A case of female headed households in Uganda. International Journal of Sciences: Basic and Applied Research, 58-69.

Dhakal, C., \& Nepal, G. (2016). Contribution of Micro-Finance on Socio-Economic Development of Rural Community. Journal of Advanced Academic Research, 3(1), 134-141.

Gupta. (2014). Who Takes the Credit? Gender, Power, and Control over Loan use in Rural 
Credit Programs in Bangladesh. World Development, 24(1), 45-63.

Hamdan, H., Othman, P., \& Hussin, W. (2012). The importance of monitoring and Entrepreneurship Concept as Future Direction of Microfinance in Malaysia: Case Study in State of Selangor. Journal of Global Entrepreneurship, 3(1).

Kamiza, P., \& Kizza, J. (2019). Microfinance products and socioeconomic growth of enterpreneurs in Uganda: A case of enterpreneurial clients of Pride Microfinance. Social Science and Humanities Journal, 03(01), 785-800.

Dąbrowska, K., Koryński, P., \& Pytkowska, J. (2020). Impact of COVID-19 Pandemic on the Microfinance Sector in Europe: Field Analysis and Policy Recommendations. Microfinance Centre (MFC).

Kizza, J., \& Ssekibaamu, A. (2019). The contribution of Luweero teachers' saving and credit cooperative organisation to teh socioeconomic welfare of teachers in Luweeo district, Uganda. International Journal of Social Science and Economic Research, 04(09), 61496178.

Kizza, J., Kasule, W., Amonya, D., Nakimuli, L., \& Komugabe, A. (2021). Perceptions Towards the Effectiveness of E-Learning in Private and Public Universities in Uganda: A Comparative Study. East African Journal of Arts and Social Sciences, 3(1), 156-169.

Magner, M. (2007, March). Microfinance: A Platform for Social Change. Grameen Foundation Publication Series. Grameen Foundation Publication Series. Retrieved October 20, 2021, from https://www.findevgateway.org/sites/default/fil es/publications/files/mfg-en-papermicrofinance-a-platform-for-social-change2007.pdf

Darin-Mattsson, A., Fors, S., \& Kåreholt, I. (2017). Different indicators of socioeconomic status and their relative importance as determinants of health in old age. International journal for equity in health, 16(1), 1-11.
Mayoux, L. (1999). Questioning virtuous spirals: micro-finance and women's empowerment in Africa. Journal of International Development, 11(7), 957-984.

Mokhtar, S. H. (2011). Microfinance Performance in Malaysia. Doctor of Philosophy, Lincoln University, New Zealand. Retrieved from http://hdl.handle.net/10182/4186

Murad, A., \& Idewele, I. O. (2017). The impact of microfinance institution in economic growth of a country: Nigeria in focus. International Journal of Development and Management Review, 12(1), 1-17.

Muzee, H., Kizza, J., \& Mugabe, G. M. (2021). Organisational Compassion and Employee Engagement in Virtual Work Environments during Covid-19 Lockdown in Uganda and Rwanda. International Journal of Management, Knowledge and Learning, 10, 127-137

Nawai, N., \& Shariff, M. (2012). Factors affecting repayment performance in microfinance programs in Malaysia. Procedia -Social and Behavioral Sciences, 62(24,806).

Postelnicu, L., \& Hermes, N. (2018). Microfinance performance and social capital: A cross country analysis. Journal of Business Ethics, 153(2), 427-445.

Rahman, A. (1999). Micro-Credit Initiatives for Equitable and Sustainable Development: Who Pays? World Development.

Sigalla, R., \& Carney, S. (2012, July 01). Poverty reduction through entrepreneurship: Microcredit, learning and ambivalence amongst women in urban Tanzania. International Journal of Educational Development, 32, 546-554.

Sinha, F. (2006). Social rating and social performance reporting in microfinance: Towards a common framework. The SEEP network.

Tavakol, M., \& Dennick, R. (2011). Making sense of Cronbach's alpha. International journal of medical education, $2,53$.

104| This work is licensed under a Creative Commons Attribution 4.0 International License. 
East African Journal of Business and Economics, Volume 4, Issue 1, 2021

Article DOI: https://doi.org/10.37284/eajbe.4.1.510

ZZamore, S., Beisland, L. A., \& Mersland, R. (2019). Geographic diversification and credit risk in microfinance. Journal of Banking \& Finance, 109, 105665.

Zheng, C., \& Zhang, J. (2021). The impact of Covid-19 on the efficiency of microfinance institutions. International Review of Economics and Finance, 71, 407-423.

105 This work is licensed under a Creative Commons Attribution 4.0 International License. 